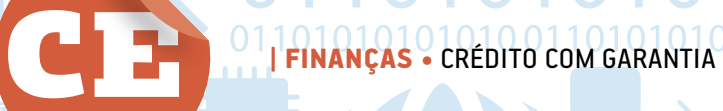

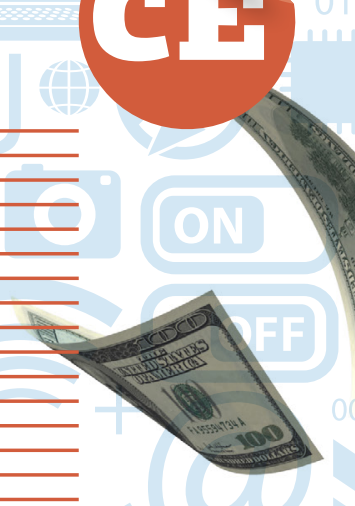




\section{CRÉDITO COM GARANTIA}

| POR RAFAEL SCHIOZER E ORLANDO VILAR

\section{Tecnologias emergentes permitem a criação de sistemas de verificação que reduzem riscos e aumentam o volume de empréstimos.}

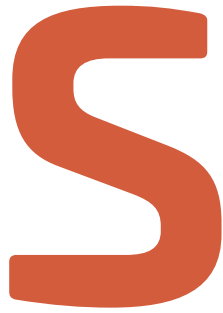

egundo estudo do Banco Mundial, não é a menor capacidade de pagamento nem a falta de ativos a serem dados como garantia (colateral) que torna o crédito a empresas em países emergentes mais escasso e mais caro do que em economias desenvolvidas. A dificuldade está nas possibilidades limitadas de as empresas, principalmente as de pequeno e médio portes, usarem seus ativos como colateral de operações de crédito.

A redução das taxas de juros cobradas nos empréstimos às corporações e o aumento da oferta de crédito em países emergentes dependem de duas condições fundamentais:

1. Um regime legal que dê ao credor o direito de acesso aos colaterais de maneira rápida e sem incertezas jurídicas;

2. Mecanismos confiáveis de verificação de garantias capazes de checar a existência e a integridade do colateral (imóvel, bem móvel ou direito creditório), bem como de identificar se um dado ativo já está servindo de colateral a outras operações de crédito.

Diversos países, incluindo o Brasil, têm conduzido reformas para melhorar o regime jurídico e desenvolvido mecanismos de verificação de garantias. Estudos mostram que, na maioria dos casos, essas mudanças e inovações tiveram sucesso em termos de:

1. Aumento no volume de crédito concedido;
2. Acesso ao mercado formal de crédito por empresas pequenas;

3. Redução do volume de colateral necessário, com ampliação na proporção entre o valor emprestado e o valor da garantia (loan-to-value);

4. Diminuição de spreads devido ao aumento do valor recuperado nos empréstimos inadimplentes - diminuição da chamada perda dada à inadimplência (loss given default);

5. E o mais importante: crescimento de investimento e emprego.

Quase todos esses efeitos são mais intensos para pequenas e médias empresas e para pessoas físicas de menor renda, que enfrentam maior restrição no acesso ao crédito.

A maior parte das pesquisas sobre o assunto enfoca as reformas nos sistemas legais de proteção a credores. Como mostra um estudo de Juliano Assunção, Efraim Benmelech e Fernando Silva, a introdução da lei brasileira de alienação fiduciária (Lei n. ${ }^{\circ} 10.931$, de 2004) no crédito de veículos permitiu aos tomadores de menor renda e profissionais autônomos mais acesso a empréstimos. A alienação fiduciária autoriza que o banco possa retomar e revender o bem (nesse caso, o veículo) sem necessidade de processo judicial.

Com relação aos mecanismos de checagem de garantias, dois estudos realizados em 2016 demonstram os efeitos da criação de sistemas de verificação de colateral de crédito 


\section{CRESCIMENTO ANUAL DE CRÉDITO PARA PESSOAS JURÍDICAS}

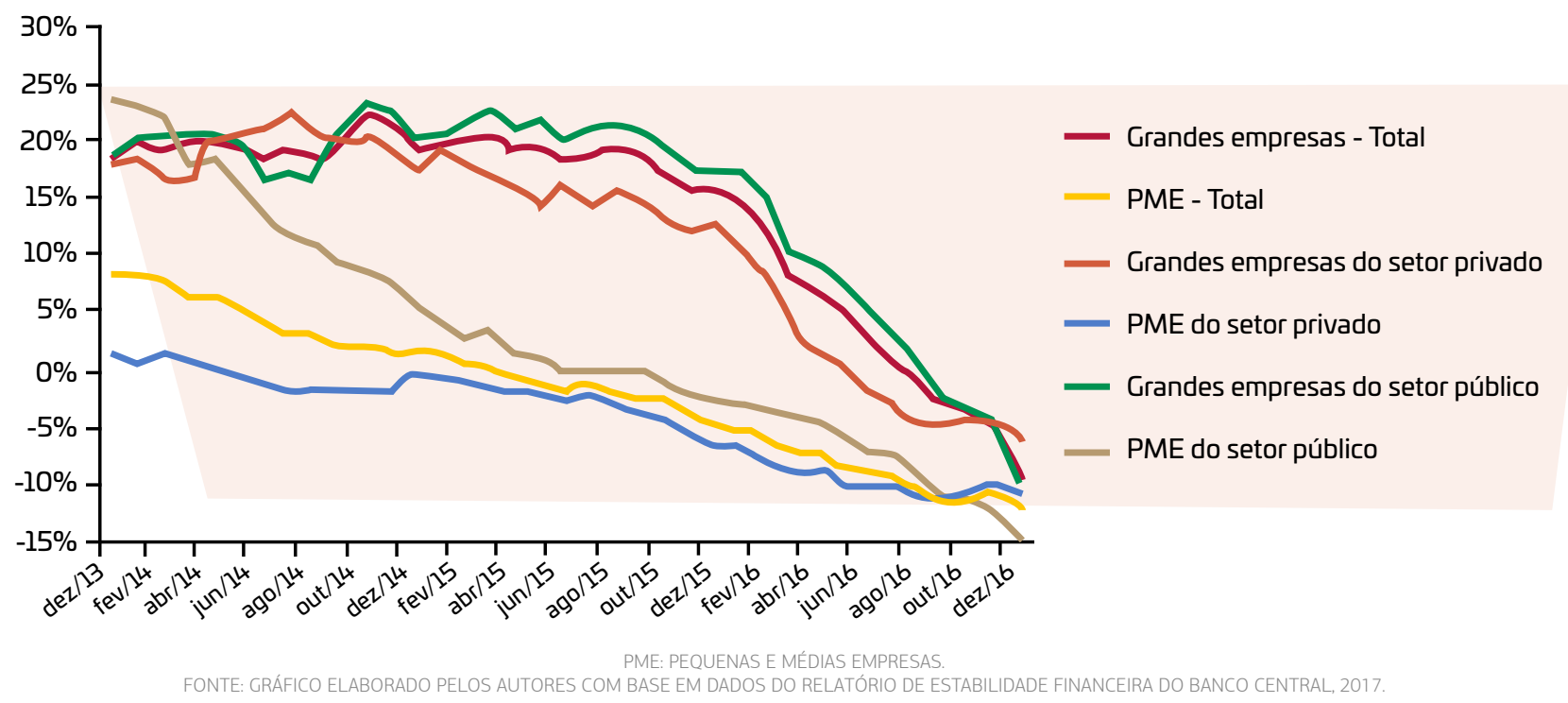

na Romênia, Bósnia, Croácia, Guatemala, Ruanda, Sérvia, Ucrânia e no Peru. Trata-se de centrais de registros de ativos físicos (máquinas e equipamentos) que checam a integridade (existência e estado de conservação) dos ativos colocados como garantias de operações de crédito. São ainda capazes de evitar que um mesmo ativo seja usado em dois bancos diferentes, o que, até então, era um grande problema enfrentado pelas instituições financeiras nesses países.

A magnitude dos efeitos da adoção dessas centrais de registros foi muito significativa: houve duplicação da oferta de crédito bancário a empresas na Romênia e aumento médio de $8 \%$ no número de tomadores nos sete países que adotaram os mecanismos em comparação a países similares que não os colocaram em prática. Além disso, as firmas aumentaram seus investimentos entre 4 e $10 \%$, e o número de empregados cresceu cerca de $3 \%$, o que mostra o impacto direto dessas centrais na economia real.

\section{CONTEXTO DE CRÉDITO ATUAL}

Não há dúvida de que as reformas legais de 2004 e 2005 (lei de alienação fiduciária e nova lei de falências), que aumentaram o poder do banco credor em retomar bens de mutuários inadimplentes, tiveram papel importante no crescimento do crédito verificado no Brasil nos últimos dez anos.

Mais recentemente, com sinais de contração da atividade econômica pelo menos desde o fim de 2012, os bancos adotaram uma postura mais conservadora e reduziram a oferta de crédito livre. Dados recentes do Banco Central mostram que o crédito a pequenas e médias empresas (PMEs) foi o mais atingido, como mostra o gráfico Crescimento anual do crédito para pessoas jurídicas. Em termos nominais, esse crédito diminuiu mais de $12 \%$ em 2016 , sendo a queda real de aproximadamente $17 \%$, considerando-se a inflação no período.

As PMEs tipicamente têm menor quantidade de ativos aceitos por bancos como garantia. Isso pode explicar, pelo menos em parte, a queda na oferta de crédito a elas. Em um contexto de instabilidade econômica, as instituições financeiras acabam priorizando operações colateralizadas. A modalidade "desconto de duplicatas" representa hoje $8,5 \%$ do crédito a pessoas jurídicas (PJs) com recursos livres - aqueles sem direcionamento obrigatório por força de lei ou regulação, como crédito imobiliário, por exemplo. Considerando-se que boa parcela das operações das modalidades "capital de giro" e "conta garantida" também é feita tendo recebíveis mercantis como colateral, é seguro afirmar que pelo menos um quinto do crédito às empresas utiliza recebíveis de operações mercantis como garantia.

Entre os principais tipos de ativos das PMEs estão os seus recebíveis de operações de crédito mercantil (duplicatas e similares). O estudo Determinantes da oferta e da demanda de créditos comerciais por micro, pequenas e 


\section{COMPOSIÇÃO MÉDIA DE CRÉDITO A PESSOAS JURÍDICAS, POR MODALIDADE, COM BASE EM RECURSOS LIVRES}

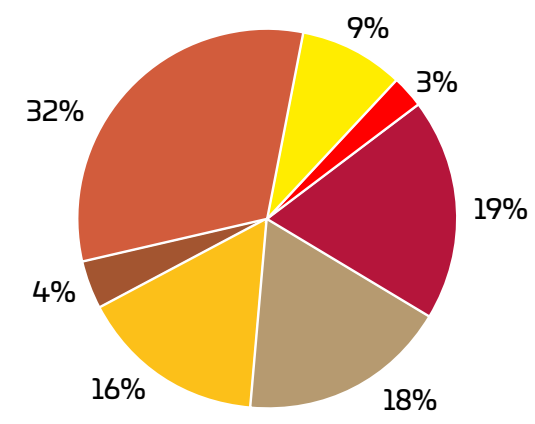

Período: entre março de 2011 e fevereiro de 2016

$\begin{array}{ll}\text { Duplicatas } & \text { Cheque especial } \\ \text { Conta garantida } & \text { Capital de giro } \\ \text { Outros } & \text { Cartão de crédito }\end{array}$

Desconto de cheques

FONTE: GRÁFICO ELABORADO.

PELOS AUTORES A PARTIR DE DADOS DO BANCO CENTRAL DO BRASIL.

médias empresas, de Claudinê Carvalho e Rafael Schiozer, mostra que os recebíveis mercantis representam, em média, $15 \%$ do total de ativos das PMEs paulistas e mineiras, percentual que pode ser ainda maior considerando o setor de serviços. No entanto, uma das barreiras à mais intensa utilização desses recebíveis é a dificuldade de verificação de sua qualidade. Há alto custo de checagem de procedência, unicidade de colateralização (se o mesmo recebível já não foi dado como garantia em outra operação de crédito) e monitoramento da garantia ao longo da vida do empréstimo, uma vez que o valor real do recebível pode ser alterado por motivos diversos, incluindo devolução do produto vendido e renegociação de prazo de pagamento. Como tal monitoramento costuma envolver checagem manual de documentação e mecanismos externos de verificação, apenas as duplicatas de maior valor, emitidas por grandes empresas, acabam se prestando a funcionar como garantia.

\section{INICIATIVAS BRASILEIRAS}

A utilização desses ativos como garantia para um número mais amplo de empresas passa necessariamente pela redução no custo de verificação de integridade dos recebíveis.
Avanços tecnológicos vêm viabilizando a criação de sistemas de registros que operam a custos substancialmente mais baixos do que no passado. Exemplos são o Sistema Nacional de Gravames (SNG) e o Sistema de Registro de Contratos de Financiamento de Veículos (Sircorf), que checam a existência e a unicidade de automóveis sob financiamento e ajudam a reduzir fraudes. Mais recentemente, foi criada a Central de Registro de Direitos Creditórios (CRDC), capaz de verificar a integridade de duplicatas e outros recebíveis mercantis.

Os mecanismos em questão são capazes de melhorar a qualidade da informação para os bancos, reduzindo, portanto, o risco das operações. Os benefícios são muitos: melhora da qualidade do crédito, eventual redução de spread e dos custos operacionais, ganho de eficiência na análise de crédito e possível aumento de seu volume.

Até o momento, o conjunto de reformas legais, em associação com mecanismos de registro de veículos, parece ter tido maior efeito no crédito imobiliário e de bens semiduráveis, como os automóveis, para pessoas físicas. A ampliação do uso de um sistema unificado de verificação de recebíveis mercantis pelos bancos terá importante papel na ampliação do crédito a empresas, especialmente o de curto prazo às PMEs. À medida que esse sistema operar com custos cada vez mais baixos, as PMES, hoje obrigadas a recorrer a mercados menos formalizados para ter acesso a crédito (como as factorings), poderão migrar para um meio mais formalizado e regulado e ter acesso a taxas de juros menores.

Finalmente, pode-se discutir uma regulação bancária que incentive os bancos a conceder crédito lastreado em duplicatas cadastradas em centrais de registro. Se o impacto da implantação de mecanismos seguros de verificação de direitos creditórios reduzir o risco de maneira relevante, a regulação pode prever menor provisionamento e alocação de capital para empréstimos lastreados nesses recebíveis.

\footnotetext{
PARA SABER MAIS:

Claudinê Carvalho e Rafael Schiozer. Determinantes da oferta e da demanda de créditos comerciais por micro, pequenas e médias empresas. Revista Contabilidade \& Finanças USP, vol. 26, n. 68, 2015.

Heywood Fleisig, Mehnaz Safavian e Nuria de la Peña. Reforming collateral laws to expand access to finance. Banco Mundial, 2006. Disponível em: goo.gl/eklbwv

Inessa Love, María Soledad Martínez Pería e Sandeep Singh. Collateral registries for movable assets: does their introduction spur firms' access to bank finance? Journal of Financial Services Research, vol. 49, n. 1, 2016.

Juliano Assunção, Efraim Benmelech e Fernando Silva. Repossession and the democratization of credit. The Review of Financial Studies, vol. 27, n. 9, 2013. Murillo Campello e Maurício Larrain. Enhancing the contracting space: collateral menus, access to credit, and economic activity. Review of Financial Studies, vol. 22, 2016.

RAFAEL SCHIOZER > Professor da FGV EAESP > rafael.schiozer@fgv.br ORLANDO VILAR > Doutorando em Administração de Empresas na FGV EAESP > orlandovilar@gmail.com
} 